\title{
Research on Legal Regulation Problem of Sharing Economy-Take Internet Chauffeured Car Service as an Example
}

\author{
Yipin Lv \\ Xinyang Agriculture and Forestry University, Xinyang, 464000, China
}

Keywords: Legal Regulation, Sharing Economy, Internet Chauffeured Car Service

\begin{abstract}
With the flourishing development of the sharing economy, more and more sharing patterns have come into the people's daily life. While sharing causes the idle resources of the society, the sharing economy meets the personalization needs of the people. However, the sustainable development of sharing economy cannot be separated from the clear and unbiased legal regulations. This paper, taking the internet chauffeured car service as an example, analyzes the principles and paths of the legal regulations of the sharing economy to provide some references for the relevant researchers.
\end{abstract}

\section{Introduction}

The sharing economy is a new type of economic model derived from practice. From the perspective of economics, the sharing economy is a rental economy mode in the internet era the transaction of direct idle resources between individuals is achieved through the Internet third party platform [1]. The essence is the temporary transfer of the right to use. The main feature of sharing economy is that businesses provide their customers with goods or services by leasing, and create a shared economic trading platform, which is available to both sides of the transaction. In a word, the sharing of the economy means that enterprises should integrate the needs of different consumers and implement centralized consumption, thus reducing waste and producing greater benefits. Of course, the sharing economy also has its own shortcomings, mainly in the sharing economy for nonprofessionals to manage, which is easy to lead to management loopholes. Although Internet tools greatly reduce the cost of both sides, the contract between the two parties is not fully protected, and the privacy information of the buyers and sellers is easy to leak. This is the malpractice of sharing the economy. In terms of the advantages of the sharing economy, this kind of shared economic company has a huge market value. Unlike the traditional corporate structure, the shared company has adopted a new development model in the new period, and this kind of company does not need to hire employees directly. This also eliminates the corporate staff's social security, pension, and so on, greatly reduce the cost of personnel, and improve the economic benefits. With the skillful application of Internet technology, the emergence of sharing platform such as drop taxi and Uber has reduced the information cost and information asymmetry with the help of effective platform by individual users. The sharing economy in the form of Internet special vehicles has officially emerged. The sharing of the economy needs legal regulation to protect consumers, public interests and public order [2].

\section{Legal Regulation Principles of Sharing Economy}

\subsection{Principle of Public}

In the context of the Internet special vehicle platform, two conflicting public resource allocation targets are restricted by the abuse of public roads and the use of idle vehicles. As the use of public power, the starting point of regulation is to serve the interests of the public. The sharing economy is closely related to people's lives, and it is easy to undertake some public service functions. For example, promoting bicycle travel to reduce pollution sharing economy is also regional, it is easier to 
carry out targeted grass-roots public services in a certain community. Therefore, it is necessary to guide the sharing economy to undertake public services. When regulating the sharing economy, we should include public considerations, guide public services by public procurement, private implementation, administration and licensing, and play public functions. The era of mobile Internet, communication and exchange between people than ever before, convenient, personal privacy problem in this process has become increasingly important; privacy should be regarded as the basic rights of a natural person, its intrinsic value is the ultimate, and is an integral part of human dignity the conditions and rights; sharing economy in convenient for people's daily life at the same time, also involves the information privacy of people; relying on a variety of mobile Internet technology to build shared economic development platform to store vast amounts of personal information, such as consumption and supply contacts, identity cards, home address, bank account number, education background so, these information basically lies in a few domestic Internet giant hands. Under the premise of effectively protecting individual information, we collect personal information of massive individuals, and use advanced technologies such as big data and cloud computing to achieve the benign development and value excavation of citizens' personal information. The principle of public nature further promotes the healthy development of the sharing economy and improves the actual experience of the consumers.

\subsection{Principle of Incentive}

The sharing economy has innovative properties, such as increasing social welfare and wide application [3]. It can revitalize low utilization assets, increase competition between buyers and sellers, reduce transaction costs, partially solve information asymmetry and stimulate traditional enterprises to improve products and services [4]. To encourage them to play the above value, the concept of innovative, friendly and innovative fault tolerance should be held in the regulation of the sharing economy. Under the premise that the shared economic innovation attribute is confirmed, the incentive regulation should be used as the core regulation strategy. Incentive regulation is the core principle of regulating the sharing economy. The principle of incentive regulation is reasonable from the view of the harm of the freedom of real right and the in incentive. The nature of the right to the right of property and the freedom of the constitution. From the perspective of property right, the owner has the right to control the property and share it for others and benefit from it. Whether it belongs to the part of the real right itself or the expansion of power is the content of the real right. From the perspective of freedom of service, freedom of labor and freedom of business, these freedoms should be naturally enjoyed by natural people. Only based on the needs of the public interest, right and freedom to limit more legitimacy. Forcibly forbidding is not the best policy. Today, with the gradual globalization of the market, forcibly prohibiting the sharing of the economy will lead to its underground operation, or lead to the existence of other licensing areas, thus forming regulatory arbitrage. In this case, we should adopt the incentive regulation strategy of sharing the economy. The specific implementation strategy of incentive regulation is to relax the threshold in terms of market access and subject qualification control, allow it to enter the market and participate in the competition. It also includes avoiding the name of permission in the formulation of specific regulatory measures, and issuing a strict standard to prohibit it.

\subsection{Principle of Difference}

Due to the different economic characteristics of different types and different areas, their impact and impact on traditional industries are also different. Therefore, the corresponding regulatory focus, regulation area and regulatory rhythm should be determined according to the industry and type characteristics. Although different forms of sharing economy involve common problems such as market access, security protection, tax regulation and so on, there are different points in the regulation of different forms of sharing economy. For example, vehicle sharing mainly involves the legal status of drivers, and tax regulation and external regulation have a greater impact on housing sharing. Moreover, the key point of regulation is whether the deposit is an illegal fund-raising. The key points of regulation are different from those of the first two types of sharing economy. In short, there are 
many types of sharing economy, there are many differences between sharing target and sharing mode. The functions of the platform are also quite different. Some of them are building transactions, building contracts and building organizations. Different types and different modes of sharing economy are faced with different problems and should be regulated differently according to different types. All kinds of special software company are not only to provide a transport supply and demand matching platform, and transportation should follow the market rules, establish brand awareness, assume responsibility should be banned, private car access platform to participate in the operation, so that the use of car passengers more comfortable, rest assured. The various car rental car software through the network platform to integrate, and according to the will of the passengers through the third-party service companies to provide driver service, service model innovation is the new period of car rental and car rental across traditional boundaries, to meet the transportation market of high quality and diversification and difference of demand has a positive effect.

\section{Legal Regulation Paths of Sharing Economy}

\subsection{Supervision Regulation Path of Sharing Economy}

As a community, the shared economic network platform involves the commonality of the interests of most of the group. To ensure public interest, the government must supervise and manage it. In addition, the business mode of sharing economy is heterogeneous. To ensure fair competition between the traditional and non-traditional companies in the industry, regulate the operation of the network platform and ensure the interests of all parties, it is necessary for the government to supervise the sharing economy. The supply and demand side of the sharing economy relies on the network platform company to complete the transaction and payment, so there is a potential risk. The regulation of the supply and demand sides of the network platform can ensure the market order. The government must establish corresponding regulatory system to prevent the sharing platform companies from abusing their regulatory power and preventing their negative effects. How to regulate the sharing economy is the government faces a challenging job, sharing economy after several years of development, the government agencies of the new business activities are still in exploring methods for the effective supervision, how to deal with a variety of choices: omission, formulation, negotiation and litigation. In addition to the negative list of market share, if market economy behavior results in line with expectations, not undermine the market order, does not infringe the rights and interests of consumers, not to harm the public interest, there is no illegal situation, it should be by the market self-regulation, the government should adopt the way of omission. If the share of the economic market is unbalanced, the government needs to take active intervention through legislation or law enforcement to formulate relevant normative documents. As for the field of the negative list, the sharing economy as a new way of market resource allocation can explore the sharing mechanism of government and market's co governance of public resources. The negotiation between government and market is a coordination mechanism between rulemaking process or litigation. It can establish communication mechanism between market and government, and achieve cooperative supervision. The lawsuit is the last means to solve all the disputes.

\subsection{Competence Regulation Path of Sharing Economy}

Based on the large-scale application of Internet technology in the field of taxi, the matching efficiency of passengers and drivers is improved. The dilemma of information asymmetry has been eliminated to a certain extent, and the negative externality of the traditional cruising mode is weakened. The British government has taken full advantage of the above conditions and loosened its control in some ways. For example, the third-party platform, depending on the specific circumstances into the scope of the license; based on the features of complete competition, private hire service quality standards in the country, the local government in the back and the right of discretion. In the car, in fact is equivalent to the British private hire. Our country can through rigorous examination of the qualifications of the platform, including the vehicle investment, personnel quality, accident 
treatment, fund and other aspects of the review, the vehicle and the driver set more stringent quality and safety standards, and then gave the car the qualification issued related business license or permit in the transportation industry, moderate open access system, but also to deal with the total control, effectively adjust the price regulation, according to the provisions of the administrative licensing law on the law of the market, not be inopportune or inappropriate to be clean. In terms of total control, on the one hand, on the basis of satisfying people's behavioral premise, the government calculates the saturation of urban capacity and taxi volume based on market monitoring and big data collection. On the other hand, the total amount control is regulated by the market, and it should be properly intervened when the market regulation is invalid. In terms of price control, we should give more control space to the market and introduce the public bargaining mechanism under the premise of effective competition. In view of the platform which has established the competitive advantage, it is necessary to prevent the predatory pricing by using the monopoly position. However, the existing enterprises can use their own resources to reverse the competition of the platform.

\subsection{Credit Regulation Path of Sharing Economy}

With the development of e-commerce, the traditional contract transaction model has been challenged. Although legitimate electronic evidence has the power of proof, it is difficult to obtain evidence, and network transactions are not limited by time and space. To a certain extent, it weakens the function of contracts to maintain e-commerce transactions and reduces the binding force to both parties. Asymmetric information is one of the important causes of market failure. The transaction information and credit evaluation of traditional transaction mode is generally limited to the parties informed. Shared economic model is the realization of information spillover and credit, the subject was informed that the transaction information and credit information is no longer limited to the parties. Follow up consumers can get information about goods, services and sellers based on the information pool built by the platform. The depth, breadth, accumulation and speed of such information are far more than traditional information disclosure. This mode can provide a large amount of information freely and efficiently, solving the problem of poor access to information before, but this information mode still has its own shortcomings. First, there is a phenomenon of information distortion. Information providers do not necessarily provide relevant information as required or provide distorted information, which may constitute concealed false propaganda. In this regard, the law should give the standards of the internal regulation of the platform, such as the mandatory platform setting information standards, and the application of platform responsibility for improper information. When the internal regulation is out of order, the law should make clear the legal consequences of the unfavorable regulation of the platform. Whether the information can be fully used depends on the subjective reasons such as the cognitive ability, cognitive habit and cognitive bias of the receiving subject. For example, when people choose to rent short houses, they may pay more attention to the crime rate of the community, while ignoring more important information such as emergency exits and fire prevention measures. In addition to the information supply link, the information digestion link also needs to be regulated by law.

\section{Conclusions}

The purpose of legal regulation to share the economy is to encourage innovation, protect consumers and pursue market efficiency. The core of the balance between multiple regulatory objectives is the game of government power and market power. It is the only way to share the sustainable development of the economy by strengthening the legal regulation and exploring the legal regulation that conforms to the market development model.

\section{References}

[1] Zhang Zhenxing, Chen Hongrui. Study of the Regulation of Internet Sharing-car from the Perspective of Market Failure [J]. Journal of Guangdong University of Finance \& Economics, 
2017(4): 104-113.

[2] Jiang Daxing, Wang Shouji. Legal Regulation of the Sharing Economy [J]. Social Sciences in China, 2017(9): 141-162+208.

[3] Peng Yue. The Legal Regulation of Sharing Economy: A Case Study on Internet Chauffeured Car Service [J]. Administrative Law Review, 2016(1): 117-131.

[4] Li Feixiang, Tan Shu. Four-Dimensional Ethical Reflections and Enlightenment Behind of the Sharing Economic Phenomenon [J]. Science \& Technology Progress and Policy, 2017(7): 1-7. 